\title{
THE ROLE AND DEVELOPMENT OF INDIRECT TAXES IN THE TURKISH TAX SYSTEM
}

\section{DOI: 10.17261/Pressacademia.2019.1086 PAP-V.9-2019(33)-p.166-170}

\section{Baris Bal ${ }^{1}$, Suat Teker}

${ }^{1}$ Ministry of Treasury and Public Finance, Istanbul Turkey. brsbal@hotmail.com, ORCID: 0000-0002-4924-1847

2Işıı Universty, Maslak Campus, Istanbul, Turkey.

suat.teker@isikun.edu.tr, ORCID: 0000-0002-7981-3121

To cite this document

Bal, B., Teker, S. (2019). The role and development of indirect taxes in the Turkish tax system. PressAcademia Procedia (PAP), V.9, p.166-170 Permemant link to this document: http://doi.org/10.17261/Pressacademia.2019.1086

Copyright: Published by PressAcademia and limited licenced re-use rights only.

\begin{abstract}
Purpose- The aim of this study is to determine the placement of indirect taxes in Turkish tax system. In order to determine the case, a compa ritive analysis of direct and indirect taxes in various countries is conducted.

Methodology- This study is conducted to reach the proposed results by using statistical data on indirect and indirect taxes. The data are observed from the web site of Revenue Administration of Turkey. In addition, the use areas of tax revenues are investigated. Findings- Significant results are obtained by comparing tax revenues of various coutires.

Conclusion- The results showed that of indirect taxes are used extensively in the sum of public revenues generated. When theses results are compared to the developed countries, it maybe concluded that the share of indirect taxes in the total tax revenues should be gradualy reduced to eliminate the negative effects of indirect taxes over the economy.
\end{abstract}

Keywords: Turkish tax system, indirect taxes, income distribution, savings.

JEL Codes: A12, D10, K34

\section{DOLAYLI VERGILERIN TÜRK VERGI SISTEMINDEKI YERI VE GELIŞiMi}

\section{ÖZET}

Amaç- Bu çalışmanın amacı, Türk vergi sisteminde dolaylı vergilerin konumunu belirlemektir. Dolaylı vergilerin toplam vergi gelirleri içindeki belirlerken, çeşitli ülkelerle karşılaştırmalar yapılmış ve dolaylı vergilerin diğer ülkelerdeki uygulama şekilleri gözden geçirilmiştir.

Yöntem- Araştırmada dolaylı vergilerle ilgili istatistiki verilerden yararlanılarak, sonuca ulaşılmaya çalışılmıştır. Ayrıca toplanan vergilerin kullanılma alanları da araştırılmıştır.

Bulgular- İstatistiki veriler resmi kurumların paylaşımlarından ve web sitelerinden elde edilmiştir. Elde edilen verilerin karşılaştırılmasıyla anlamlı sonuçlar ortaya çıkmıştır.

Sonuç- Yapılan araştırma sonucunda, Türkiye' de dolaylı vergilerin çok yoğun bir şekilde kullanıldığı gözlemlenmiştir. Diğer gelişmiş ülkelerle karşılaştırıldığında, bu yoğunluğun kademli olarak azaltılması ve dolaylı vergilerin bireyler üzerindeki olumsuz etkilerinden arındıııması öneril mektedir.

Anahtar Kelimeler: Türk vergi sistemi, dolaylı vergiler, kayıt dışılık, gelir dağılımı, tasarruflar.

JEL Kodları: A12, D10, K34

\section{GíRiş}

Bireylerin yaşamlarını sağııklı bir şekilde idame ettirebilmeleri için bir arada yaşamaları gerekir. Bir arada yaşarken sahip olunan topluluğun yönetilmesi için, belirli ihtiyaçlara cevap verebilecek bir organizmanın varlığı gerekecektir. Bu noktada devlet organizması ortaya çıkmaktadır. Devletin hareket imkânına sahip olabilmesi içinse gelir kaynaklarına ihtiyacı vardır. Devletlerin gelir kaynakları arasında en önemli payı ise vergi gelirleri oluşturmaktadır. Vergi gelirlerinin devletler için taşıdığı önem bu noktada ortaya çıkmaktadır. Her devlet daha rahat hareket 
imkânına sahip olabilmek için gelirlerini artırma yoluna gitmektedir. Vergi gelirleri devletlerin en önemli gelir kaynakları olduğundan, uygulama açısından sürekli güncellenerek maksimum verim sağlanmaya çalışılmaktadır.

Vergi sistemleri ülkeler tarafından kurgulanırken, çeşitli faktörler etkili olmaktadır. Bu faktörlere örnek olarak; siyasi, sosyal, kültürel ve coğrafi farklılıklar gösterilebilir. Bu farlılıklar vergi sistemlerinin oluşmasında önemli rol oynamaktadır. Vergi sistemleri, farkl ı konulardan alınan vergi türlerinden meydana gelmektedir. Vergiler birbirinden ayırt edilirken, çeşitli kıstaslara tabi tutulmaktadırlar. Vergilerin sınıflandırılmasında kullanılan en yaygın yollardan biri de dolaylı dolaysız vergi ayrımıdır. Dolaylı vergiler kişilerin her türlü tüketim mallarına uygulanan, satıcısından veya üreticisinden alınan, fiyatlara eklenerek nihai tüketiciye yansıtılan vergilerdir. Bu vergiler; yansıtılabilmesi, fiyatların içine gizlenebilmesi ve peşin olarak tahsil edilebilmesi gibi sebeplerden ötürü sıkça tercih edilirler. Ülkemizde dolaylı vergilerin gelişim sürecine bakıldığında ise, geçmişten günümüze dolaylı vergilerin ağılık kazandığı bir yapının ortaya çıktığı görülmektedir.

Günümüzde; az gelişmiş ve gelişmekte olan ülkelerde dolaylı vergilerin daha yoğun bir şekilde uygulandığı görülmektedir. Dolaylı vergilerin uygulanabilirliğinin kolay olması ve vergi sistemi kurma zahmetine girmeden daha basit bir yapıda tahsil edilebilmesi, az gelişmi ş ve gelişmekte olan ülkelerin dolaylı vergileri tercih etmesine sebep olmuştur. Bunun yanında tasarruf yapmanın gelişmiş ülkelere nazaran daha zor olduğu, az gelişmiş ve gelişmekte olan ülkelerde yüksek gelir elde eden grupların daha kolay tasarruf yapabilmesi içinde dolaylı vergiler tercih edilebilmektedir.

Dolaylı vergilerin vergi sistemleri içinde ağırlıklı olarak yer alması çeşitli ekonomik göstergelere etki etmektedir. Vergilerin vatandaşlar üzerindeki etkisi kaçınımazdır. Vergi sistemlerinin yapısı tahsil edilen vergilerin vatandaşlar üzerinde oluşturacağı etkiyi belirlemektedir. Dolaylı vergilerin vatandaşların gelir durumla rını göz önüne almadan uygulanıyor olması, birçok açıdan önemli etkilere sebebiyet vermekte dir. Dolaylı vergilerin vergide adalet kavramını zedelemesi vergi sistemlerini tartışılır hale getirmektedir. Bunun yanında dolaylı vergilerin çeşitli makroekonomik etkileri de vardır.

\section{LITERATÜR INCELEMESI}

Vergi; devletin ve yetkili diğer kamusal kurum ve kuruluşlarının, mali ve mali olmayan görevlerini yerine getirebilmeleri ama cıyla, gerçek ve tüzel kişilerden; cebri, karşılıksız olarak ve egemenlik gücüne dayanarak tahsil ettiği para şeklindeki iktisadi kıymetlerdir. Bir başka anlatım ile vergi, kamusal giderleri karşılamak üzere herkesin mali gücüne göre ödemekle yükümlü olduğu ekonomik bir değerdir.

Musgrave'e göre ise vergi; devletlerin sosyal nitelikli mal ve hizmetler için ihtiyaç duyduğu malların satın alımını ve kamuda çalışan personele yapılan maaş, harcırah vb. ödemeleri finanse edebilmek için egemenlik gücüne dayanarak yaptıkları bir kaynak transferidir. Musgrave'in yapmış olduğu bu tanımda daha çok verginin ekonomik özellikleri üzerinde durulmuştur.

Ikemiz vergi mevzuatı irdelendiğinde, 213 sayılı Vergi Usul Kanunumuzda vergi kavramının tanımlanmamış olduğu görülmektedir. Bununla birlikte, Anayasamızın 73. maddesinde "herkes kamu giderlerini karşılamak üzere, mali gücüne göre vergi ödemekle yükümlüdür. Vergi, resim, harç ve benzeri mali yükümlül ükler ancak kanun ile konulur, değiştirilir veya kaldırılır." şeklindeki vergi ödeme yükümlülüğü kavramı ile dolaylı olarak vergi müessesesinin tanımı yapılmıştır. Şöyle ki, Anayasamızın ilgili maddesine göre verginin temel özellikleri, kamusal giderleri karşılamak, mükelleflerin ödeme güçleri ile orantılı olmak ve bir kanun ile tahsil edilmektir.

Vergi gelirleri, devletlerin oluşturdukları politikaları uygulayabilmeleri için kaçınılmaz olarak sahip olmaları gereken bir araçtır. Bu araçların verimli olarak işlevlerini yerine getirebilmesi de vergi sistemlerinin sorunsuz bir şekilde işlemesine bağlıdır. İstenilen ve beklenilen düzeylerde vergi hasılatı elde edilememesi durumunda devlet politikaları etkilenecektir. Dolayısıyla ülke yönetimine dair aksaklıklar ortaya çıkacaktır. Devletler geleceğe dair planlarını beş yıllık, on yıllık, yirmi yıllık planlar halinde yaparlar. Bu planların oluşturulmasındaki en önemli etkenlerden bir tanesi de vergi gelirleridir. Çünkü vergiler devletlerin hareket kabiliyetlerini etkilemekte ve bu durumda tüm ekonomiye tesir etmektedir.

Vergi gelirlerinin kamusal hizmetlerde kullanılması gibi temel işlevi mevcut olsa da kuşkusuz bunun dışın da birçok alanda etkisi vardır. Vergiler ekonomik göstergelerin oluşmasında da çok önemli bir yere sahiptir. Bütün bunlar birlikte düşünüldüğünde vergilerin kamu gelirleri içindeki payının önemi artmaktadır.

\section{YÖNTEM}

Dolaylı vergiler kişilerin her türlü tüketim mallarına uygulanan, satıcısından veya üreticisinden alınan, fiyatlara eklenerek nihai tüketiciye yansıtılan vergilerdir. Bu vergiler; yansıtılabilmesi, fiyatların içine gizlenebilmesi ve peşin olarak tahsil edilebilmesi gibi sebeplerden ötürü sıkça tercih edilirler. Dolaylı vergiler sadece yurt içindeki ticari işlemlerden değil, yurt dışındaki ticari işlemlerden de alınır. Buna göre dolaylı vergileri; dâhilde alınan vergiler, dış ticaretten alınan vergiler ve diğer vergi türleri olarak ayırmak mümkündür. 


\begin{tabular}{|c|c|}
\hline \multicolumn{2}{|r|}{ 1923- 2018 Yılları Dolaylı Vergilerin Gelişim Süreci Özet Tablo } \\
\hline 1923- 1950 & $\begin{array}{l}\text { Cumhuriyetin kurulmasıyla birlikte uygulanacak olan ekonomik politikaların belirlenmesi amacıyla } 1923 \\
\text { yılında İzmir iktisat Kongresi toplanmışıtır. } 1925 \text { yılında Osmanlıdan kalan ve bazı sorunlara yol açan Aşar } \\
\text { Vergisi kaldırılmıştır. Ortaya çıkan bu boşluk uyum sorunlarının minimum ol ması nedeniyle dolaylı vergiler } \\
\text { yoluyla giderilmeye çalışıımışır. Bu dönemde dışarıya kapalı, korumacı bir politika uygulanmış; bu sebeple } \\
\text { dış ticaret üzerinden elde edilen vergi gelirleri zamanla azalmışır. }\end{array}$ \\
\hline 1950- 1980 & $\begin{array}{l}1950 \text { yılında yapılan seçimle Cumhuriyetin kurulmasından itibaren ülkeyi yöneten iktidar değişmiş, bu değişim } \\
\text { uygulanan politikalarda farklııklar oluşmasına sebep olmuştur. } 1950 \text { yılından itibaren başlayan dönemde, dış̧ } \\
\text { ticarette uygulanan serbestleşme modelinin sonucu olarak, iç pazara yönelik bir sanayileşme hamlesi değil, } \\
\text { dış pazarlara yönelik, tarıma, madenciliğe, inşaat sektörüne ve alt yapı yatıımlarına ön plana alan bir } \\
\text { kalkınma modeli uygulanmıştır. } 1950 \text { yılında Gelir Vergisi, Kurumlar Vergisi, Esnaf Vergisi Kanunu ve Vergi } \\
\text { Usul Kanunlarının çıkarılmıştır. } 1956 \text { yılında muamele ve tüketim vergileri yürürlükten kaldırılmıştır. Bunların } \\
\text { yerine Gider Vergileri Kanunuyla birlikte dört yeni vergi, vergi sistemine dâhil olmuştur. Bu dönemde } \\
\text { yürürlüğe giren gelir kanunlarının etkisiyle vergi gelirlerinde gelir üzerinden alınan vergilerin payı artarken } \\
\text { tüketim vergilerinin payı azalmıştır. }\end{array}$ \\
\hline 1980- 1994 & $\begin{array}{l}1980 \text { yılından sonra ülkede dışa açılma politikası izlenmiştir. Uluslararası finans kuruluşları ve özellikle de } \\
\text { International Monetary Fund (IMF) ile çalışılmaya başlanılmış ve destek alınmıştır. Devletin ekonomiye } \\
\text { müdahalesi azalmış, finansal özgürlük sağlanmaya çalışılmış, ihracat teşvikleri verilmiş ve bazı vergi oranları } \\
\text { düşüürülmüştür. } 1985 \text { yılında Katma Değer Vergisi Kanunu yürürlüğe girmiştir. KDV'nin uygulanabilirliğine } \\
\text { katkı sağlamak amacıyla Ücretlilere Vergi ladesi Hakkında Kanun ve KDV mükelleflerine aşamalı bir şekilde } \\
\text { ödeme kaydedici cihaz kullanma mecburiyeti getiren } 3100 \text { sayılı Kanun yürürlüğe girmiştir. KDV'nin yürürlüğe } \\
\text { girmesiyle beraber dolaylı vergilerin vergi gelirleri içerisindeki payı giderek artış göstermiştir. }\end{array}$ \\
\hline 1994- 2002 & $\begin{array}{l}\text { Bu dönemde } 5 \text { Nisan } 1994 \text { tarihindeki ekonomik krizin sonrasında kamu kesiminde oluşan nakit ihtiyacını } \\
\text { karşılayabilmek için bir kereye mahsus olacak şekilde olağanüstü vergiler yürürlüğe girmiştir. } 04.05 .1994 \text { tarih } \\
\text { ve } 3986 \text { sayılı "Ekonomik Denge İçin Yeni Vergiler Ihdası... Hakkında Kanun'la "Ekonomik Denge Vergisi”, "Net } \\
\text { Aktif Vergisi”, "Ek Gayrimenkul Vergisi”, "Ek Motorlu Taşıtlar Vergisi” şeklinde dört adet vergi kanunlaşmıştır. } \\
5 \text { Nisan } 1994 \text { tarihinde ortaya çıkan kriz sonrası gerçekleştirilen politikalardan beklenenleri; fiyatlar genel } \\
\text { seviyesindeki sert yükselişi dizginlemek, ekonominin normal seyrine dönebilmesi için uygun bir ortam tesis } \\
\text { etmek, büyümeyle beraber çeşitli iş imkânlarına olanak sağlamak ve iktisadi olarak bir istikrar dönemine } \\
\text { girerek belirlenen politikalara odaklanmak şeklinde sıralamak mümkündür. Bu dönemde siyasi ve iktisadi } \\
\text { krizlerin etkisinden bir türlü çıkılamamış, uygulanmak istenen planlarda başarı sağlanamamışıtır. Tüm bunlara } \\
\text { bağlı olarak vergi gelirlerinde sistemli bir uygulama gerçekleştirilememiştir. Dolaylı vergilerin vergi gelirleri } \\
\text { içerisindeki payı her geçen yıl artış göstermiştir. }\end{array}$ \\
\hline 2002- 2018 & $\begin{array}{l}2002 \text { yılına gelindiğinde yıllardır süren koalisyon hükümetlerinden sonra tek başına iktidar hükümet ol muştur. } \\
\text { Acil Eylem Planı uygulamaya konulmuş; mali önlemler, özelleştirme çalışmaları, reel sektörün yeniden } \\
\text { düzenlenmesi, yapısal reformlar içeren tedbirler ile cari açıı̆a iliş̧in önlemler bu planın ana hatlarını } \\
\text { oluşturmuş̧ur. 06.06.2002 tarihinde kabul edilen } 4760 \text { sayılı Özel Tüketim Vergisi Kanunu ile KDV'nin } \\
\text { uygulanmakta olduğu genel orandan daha yüksek oranda vergilendirilen çeşitli mallar bu kapsama alınmıştır. } \\
\text { Bu dönemde beş adet vergi barışı kanunu çıkarılarak vergi mükelleflerine oldukça avantajlı imkânlar } \\
\text { sunulmuştur. Dolaylı vergilerin vergi gelirleri içerisindeki payı ise azda olsa artış göstermiş̧ir. }\end{array}$ \\
\hline
\end{tabular}

Dolaylı vergilerin tercih edilme sebepleri; toplumun tüm kesimlerine uygulanabilir olması, gelir potansiyelindeki yükseklik, tahsil maliyetlerinin düşük olması, tasarrufları teşvik edici olması, tüketim tercihlerine etkisi, vergi kaçakçılığının güç olması, mükellef psikolojisi üzerindeki etkileri olarak sıralanabilir.

\section{BULGULAR}

Dolaylı vergiler özellikle gelişmekte olan ülkelerde, vergi gelirleri içinde büyük paya sahiptirler. Bu sebeple dolaylı vergileri sadece bir gelir kaynağı olarak değil, iktisadi bir etken olarak da değerlendirmek gerekir. Bu bölümde dolaylı vergilerin ekonomik yansımaları çeşitli faktörler dâhilinde değerlendirilecektir.

Vergi ve devlet ilişkisinde ilk akla gelen, devletin harcamalarına kaynak oluşturmak için vergilere başvurduğudur. Fakat vergiler en başta bu amaçlarla koyulmuş olsa da zamanla vergilerin çeşitli müdahale etkileri ortaya çıkmıştır. Buna göre 19. Yüzyıldan sonra verg inin müdahale aracı olma özelliklerinin de ortaya çıkmasıyla beraber, vergiler iktisadi ve sosyal yaşama müdahalenin de bir aracı haline gelmişlerdir.

Vergilerin ekonomik ve sosyal yaşama müdahale aracı olmasının temelinde, milli gelire ortak olması durumu etkilidir. Devlet koymuş olduğu vergilerle vatandaşların gelirlerine uygulanmakta olan vergi oranları kadar ortak olmaktadır. Benzer şekilde vatandaşların ya pmış oldukları harcamalar üzerinden de vergiler yoluyla gelir elde etmektedir. Devletin bu şekilde vatandaşların gelir ve ha rcamaları üzerinde etkili olması, 
vatandaşların gelir elde etme ve ha rcamalarında çeşitli etkilere sebep olmaktadır. Gelişmekte olan ülkelerde vergi gelirleri içerisinde en büyük pay dolaylı vergilere aittir. Bu sebeple, iktisadi ve sosyal açıdan da dolaylı vergilerin etkileri daha büyük olmaktadır.

\section{SONUÇ VE ÖNERILER}

Bireylerin tasarruf edebilmesi için temel ihtiyaçların fiyatını artıran dolaylı vergilerde düzenlemeye gidilmelidir. Aynı şekilde enflasyonun düşük seviyelerde seyretmesi için dolaylı vergilerin temel tüketim alanlarındaki ağırlığı azaltılmalıdır. Büyüme hedefi, tasarruf ve yatırımlarla beraber belirlenmelidir. Bunun için vergilerin tasarruf ve yatırımlar üzerindeki etkisi iyi göz önüne alınmalıdır.

Dolaylı vergilerin yoğunluğu mükellefleri kayıt dışılığa itmektedir. Kayıt dışılığın azaltılması için adaletsiz bir yapı arz eden dolaylı vergilerden dolaysız vergilere kademeli olarak geçiş sağlanmalıdır. Gelir Vergisinin vergi gelirleri içindeki payı, beyana dayalı gelir vergisinin gelir vergisi içindeki ağırlığıyla birlikte artırılmalıdır. Gelir vergisi tarifesindeki en yüksek oran \%40'a çıkarılmalıdır. Dilimler arası tutarlar genişletilmelidir.

Mülkiyet üzerinden alınan vergilere ağırlık verilerek vergi gelirleri içindeki payı arttırılmalıdır. Sosyal transfer harcamalarının gelir dağılımındaki adaletsizliğe bir pansuman olduğu düşünülerek, bu harca maların artırılması gerekmektedir.

\section{KAYNAKLAR}

Akdoğan, A. (2002). Kamu Maliyesi. Gazi Kitabevi, Ankara.

Akıncı, A., Özçelik, Ö. (2018). Türkiye'de Dolaylı Vergilerin Enflasyon Üzerindeki Etkisi, Maliye ve Finans Yazıları - (110).

Aksoy, Ş. (2011). Kamu Maliyesi. Gözden Geçirilmiş ve İlaveli 4. Baskı, İstanbul, Filiz Kitabevi.

Aydın, F. (2001). Vergide Konu Seçiminin Verginin Amaç ve Fonksiyonları Açısından Analizi - I, Vergi Sorunları Dergisi, Sayı:156.

Boratav, K. (2010). Türkiye İktisat Tarihi 1908-2007, 14. Baskı, Ankara, İmge Kitabevi.

Bulutoğlu, K. (2003). Kamu Ekonomisine Giriş, YKY Yayınları, İstanbul.

Bulutoğlu, K. (2004). Türk Vergi Sistemi. İstanbul, Batı Türkeli Yayıncılık.

Buyrukoğlu, S., Buzkıram D. (2016). İnsan Ve Toplum Bilimleri Araştırmaları Dergisi. Cilt: 5, Sayı: 7.

Cansız, H. (2014). Defterdarlık Çalışanlarının Vergileme İlkelerine Bakışı, AKÜ iïBF Dergisi, Cilt XVı, Sayı:2, 34.

Çağan, N. (1982). Vergilendirme Yetkisi, İstanbul, Kazancı Hukuk Yayınları.

Devrim, F. (2002). Kamu Maliyesine Giriş, İzmir, Anadolu Matbaacılık.

DPT, (2001), Sekizinci Beş Yıllık Kalkınma Planı, Kayıt Dışı Ekonomi Özel İhtisas Komisyonu Raporu, Ankara.

Durmuş, M. (2003). Maliye Politikaları Teori ve Uygulamalarının Değerlendirilmesi, Yaklaşım Yayınları, Ankara.

Durkaya, M., Ceylan, S. (2006). “Vergi Gelirleri ve Ekonomik Büyüme”, Maliye Dergisi, Sayı:150.

Durmuş, M. (2004). "Vergi Sistemleri ve Temel Belirleyicileri”, Yaklaşım Dergisi, Sayı:135, 2004.

Edizdoğan N., (2011), Kamu Maliyesi, 3. Baskı, Bursa, Ekin Kitabevi.

Erginay, A. (1998). Kamu Maliyesi. 16. Baskı, Ankara, Savaş Yayınları.

Garner, C. Alan. (2005). “Consumption Taxes: Macroeconomic Effects and Policy Issues” Çevrimiçi: ttps://www.kansascityfed.org/PUBLICAT/ECONREV/PDF/2Q05garn.pdf Erişim: 20.02.2019.

Gökbunar, A. R. (1998). “Vergileme İlkeleri ve Küreselleşme” ,CBÜ. iliBF Yön. ve Ekonomi Dergisi.

Göker, C. (2011), Yönlendirici Vergilendirme. Ankara, Turhan Kitabevi.

Kanlı, M. (2007). “Dolaylı Vergiler ve Kayıt Dışı Ekonomi”. Marmara Üniversitesi Sosyal Bilimler Enstitüsü. İstanbul.

Kırbaş, S. (1991). “Çeşitli Yönleriyle Vergileme ve Türk Vergi Sistemi”. Sayıştay Dergisi, Sayı: 3.

Kırman, A. (2001). Banka ve Sigorta Muameleleri Vergisi, Ankara, Cem Web Ofset.

Kızılot, Ş. (1998), Katma Değer Vergisi Kanunu ve Uygulaması, Yaklaşım Yayınları, Ankara.

Saraçoğlu, F. (2006). "KDV’nde Oransal Yapı ve Vergi Oranlarında Yapılan Değişikliklerin Tüketim ve Tasarruflar Üzerindeki Etkisi”, Sayıştay Dergisi, No.62.

TÜSIAD. (2012). Dolaylı ve Dolaysız Vergilerin Türk Mali Sistemi İçindeki Yeri: Siyasal,

Sosyal ve Ekonomik Sonuçları. İstanbul, TÜsiAD.

Tosuner, M., Arıkan, Z. (2008). Türk Vergi Sistemi, İzmir, Neşa Ofset Yayınları, s. 9-10. 
Vergilemenin Ekonomik Büyüme Üzerindeki Etkileri: Türkiye'deki Durumun Analizi. T.C. Maliye Bakanlığı Araştırma, Planlama ve Koordinasyon Kurulu Başkanlığı. Yayın No: 2004/365. Ankara.

Yaraşlı, G. O. (2003) Türkiye'de Vergi Reformu, T.C. Maliye Bakanlığı Araştırma, Planlama ve Koordina syon Kurulu Başkanlığı, Ankara.

Yereli. A. B. Ata A. Y. “Vergi Adaletine Ulaşma Yöntemleri Çerçevesinde Fayda İlkesinin Teorik Açıdan Değerlendirilmesi” , Maliye Dergisi,

Sayı 161, Temmuz -Aralık 2011.

YILMAZ Hakan, (1996) Türkiye'de Vergi Yapısı ve 1980’den Sonra Sektörel Vergi Yüklerinin Gelişimi, Uzmanlık Tezi, DPT.

Uluatam, Ö. (1999). Kamu Maliyesi, Ankara, İmaj Yayıncılık.

Yüce, M. (2004). "Avarız Vergisinin Muhteşem Dönüşü: Olağanüstü Vergiler", Akademik Bakış Dergisi, Sayı:3, Temmuz 2004. 